\title{
O CICLONE IDAI E OS DESAFIOS DA AJUDA HUMANITÁRIA EM MOÇAMBIQUE ${ }^{1}$
}

\author{
Pedro Andrade Matos ${ }^{2}$ \\ Escola Superior Dom Helder Câmara (ESDHC)
}

Anastásio Miguel Ndapassoa ${ }^{3}$

Universidade Católica de Moçambique (UCM)

\section{RESUMO}

Na noite entre os dias 14 e 15 de março de 2019, a região central de Moçambique, em particular a cidade da Beira e regiões vizinhas, foi devastada por um ciclone batizado de Idai, provocando uma situação de calamidade natural e de ajuda humanitária. O presente artigo visa analisar em que medida o governo moçambicano foi capaz de coordenar as ações e garantir a proteção aos direitos humanos das pessoas afetadas e, ao mesmo tempo, se resguardar dos desafios inerentes às ajudas, especialmente a ingerência interna. A metodologia do trabalho foi dedutiva, baseando-se no método qualitativo e no estudo de caso do referido fenômeno. As fontes consultadas se referem aos relatórios oficiais pós-desastre Idai e à análise da literatura especializada, nomeadamente livros e artigos científicos.

Palavras-chave: ajuda humanitária; ciclone Idai; desastre natural; Moçambique.

1 O presente trabalho foi realizado em parte com apoio da Coordenação de Aperfeiçoamento de Pessoal de Nível Superior - Brasil (CAPES) - Código de Financiamento 001.

2 Estágio pós-doutoral no âmbito do Programa Nacional de Pós-Doutorado (PNPD-CAPES) na ESDHC. Doutorado em Relações Internacionais - Política Internacional pela Pontifícia Universidade Católica de Minas Gerais (PUC-MINAS). Mestrado em Ciência Política pela Universidade Federal de Minas Gerais (UFMG). Graduação em Relações Internacionais pela PUC-MINAS. Docente da disciplina Energia, Meio Ambiente e Globalização no Programa de Pós-Graduação em Direito Ambiental e Desenvolvimento Sustentável da ESDHC. Membro e um dos idealizadores do Centro de Estudos Afro-Brasileiros (AFRODOM) da ESDHC. ORCID: https://orcid.org/0000-0003-1949-4138 / e-mail: matooscv@hotmail.com

3 Doutor em Direito pela Faculdade de Direito da Universidade do Porto. Mestre em Direito Internacional público pela Universidade de Kiev. Especialista em Direito Internacional Público pelo CEDIN-BH. Docente das disciplinas Direito Internacional Público, Direitos Humanos e Direito de Integração Regional na UCM. Coordenador de equipa de Moot Court da UCM (Julgamentos fictícios em África organizados pelo Centre for Human Rigths of University of Pretoria). Advogado, membro da Ordem dos Advogados de Moçambique. E-mail: am.ndapassoa@gmail.com; ndapassoa@tdm.co.mz. 


\section{CYCLONE IDAI AND THE HUMANITARIAN AID CHALLENGES IN MOZAMBIQUE}

\section{ABSTRACT}

On the night of the 14th to 15th of March 2019, the central region of Mozambique, in particular the city of Beira and surrounding regions, was devastated by a cyclone named Idai, causing a situation of natural calamity and humanitarian aid. This article aims to analyze the extent to which the Mozambican government has been able to coordinate actions and guarantee the protection of the human rights of those affected and, at the same time, to guard against the challenges inherent in aid, especially internal interference. The work methodology was deductive, based on the qualitative method and the case study of the referred phenomenon. The sources consulted refer to the official post-Idai disaster reports and analysis of the specialized literature, namely books and scientific articles.

Keywords: Cyclone Idai; Humanitarian Aid; Mozambique; Natural Disaster. 


\section{INTRODUÇÃO}

Na noite entre os dias 14 e 15 de março de 2019, a região central de Moçambique, em particular a cidade da Beira e regiões vizinhas, foi devastada por um ciclone batizado de Idai. O ciclone foi de intensidade 4 (na escala de Saffir-Simpson), com ventos de mais de $240 \mathrm{~km} / \mathrm{h}$, acompanhado por chuvas intensas. Para agravar a situação, os rios Pungue e Búzi, que deságuam na baía da cidade da Beira, registraram cheias alagando extensas áreas rurais e vilas. $\mathrm{O}$ balanço da passagem ciclônica resultou em mais de 600 vítimas mortais e vultosos prejuízos materiais, provocando uma situação de estado de calamidade natural e humanitária.

Perante a crise humanitária que se seguiu ao ciclone Idai e a pronta resposta da comunidade internacional, o presente artigo visa analisar em que medida o governo moçambicano foi capaz de coordenar as ações e garantir a proteção aos direitos humanos das pessoas afetadas e, ao mesmo tempo, se resguardar dos desafios inerentes às ajudas, especialmente a ingerência interna.

Moçambique é um dos países africanos mais vulneráveis a eventos climáticos extremos, quais sejam, ciclones, cheias, inundações e secas, agudizando a vulnerabilidade e a capacidade de resposta do Estado para catástrofes. De fato, a pobreza econômica limita sobremaneira a capacidade desse Estado em estabelecer planos e políticas efetivas de prevenção, mitigação e adaptação às mudanças climáticas, tendo em vista, em primeiro lugar, a salvaguarda de direitos humanos fundamentais.

Do ponto de vista do Direito Internacional Humanitário, a responsabilidade de proteger os cidadãos e seus direitos perante uma catástrofe natural repousa, em primeira instância, sobre o estado afetado. Caso seja manifestada incapacidade de sua parte, a solução consiste, muitas vezes, em solicitar ajuda humanitária internacional para socorrer as vítimas.

As ações humanitárias que se seguem à ocorrência de um desastre natural são de tal intensidade e dimensão que acabam gerando problemas de coordenação ao país, obrigando-o, em muitos casos, a compartilhar a liderança de coordenação das operações de assistência com atores externos. Nesse contexto, surge mais um dilema: tendo solicitado a ajuda humanitária, o Estado se vê desafiado a se defender das armadilhas da ajuda humanitária contra uma possível ingerência estrangeira nos assuntos internos.

O objeto geral deste trabalho é analisar os desafios da ajuda humanitária para o alívio de desastres naturais em países pobres. Os objetos 
específicos visam examinar a coordenação moçambicana nesse fluxo de ajuda e a garantia dos direitos humanos das pessoas afetadas pelo referido desastre natural.

A metodologia do trabalho foi dedutiva, baseando-se no método qualitativo e no estudo de caso do ciclone Idai na cidade da Beira. As fontes consultadas se referem aos relatórios oficiais pós-desastre Idai e análise da literatura especializada, nomeadamente livros e artigos científicos.

$\mathrm{O}$ artigo encontra-se organizado em quatro seções, ademais desta introdução e da conclusão. A primeira contextualiza o ciclone Idai, ressaltando os danos humanos e ambientais. A segunda seção analisa as respostas governamentais de prevenção e adaptação às mudanças climáticas pré-ciclone Idai. A terceira seção examina as ações e ajudas humanitárias no âmbito do ciclone Idai e a participação do governo na coordenação e execução dessas ações e ajudas. A última seção trata dos desafios e armadilhas da ajuda humanitária, entendendo o contexto do desastre como gerador de desafios e problemas entre os atores que pretendem salvar a vida e garantir os direitos fundamentais das pessoas afetadas.

\section{CONTEXTO DO CICLONE IDAI: DANOS AMBIENTAIS E HUMANOS}

Neste trabalho, os danos ambientais se referem, de maneira individual e coletiva, aos aspectos natural, artificial e cultural do meio ambiente; enquanto danos humanos abrangem o número de óbitos, enfermos, feridos, desabrigados, desalojados, desaparecidos e afetados pelo ciclone Idai.

Os danos variam conforme o grau da vulnerabilidade que abrange aspectos socioeconômicos e ambientais de uma determinada região, o que permite afirmar que os desastres não são naturais, ainda que sejam provocados por fenômenos naturais: eles são resultado do tipo de relações sociais mantidas com a natureza. Por isso, importa a este trabalho contextualizar o planejamento do governo moçambicano relativamente a eventos potencialmente catastróficos. $\mathrm{O}$ argumento provisório aponta que a ausência de planejamento eficiente é prejudicial sobretudo aos grupos vulneráveis, que correm o risco de violações dos direitos humanos, bem como ao meio ambiente.

Moçambique situa-se na costa oriental da África Austral e é banhado pelo Oceano Índico. É dos países com a mais extensa costa marítima do 
continente africano: $2.515 \mathrm{~km}$ do norte ao sul. Este fato, que é certamente uma grande vantagem em termos econômicos e turísticos, apresenta, porém, custos com a proteção costeira e alta exposição aos fenômenos meteorológicos que se formam no Oceano Índico. Pela sua localização geográfica, Moçambique constitui-se em uma espécie de porta de entrada desses fenômenos quando se direcionam à região austral do continente.

$\mathrm{Na}$ noite entre os dias 14 e 15 de março de 2019, a região central de Moçambique $^{4}$ foi assolada pelo ciclone Idai, com ventos fortes, entre 180 e $240 \mathrm{~km} / \mathrm{h}$, e chuvas intensas de mais de $200 \mathrm{~mm} / 24$ horas. No dia 25 de abril de 2019, alguns distritos das províncias da região norte do país (Cabo-Delgado e Nampula) foram assolados pelo ciclone Kenneth. Este ciclone vinha acompanhado de rajadas de vento com até $220 \mathrm{~km} / \mathrm{h}$, mas perdeu intensidade ao atingir a terra (INGC, 2019).

Dos dois ciclones, o Idai foi o que mais prejuízo provocou na região central de Moçambique. Por onde este ciclone passou deixou um rastro de morte e destruição que se saldou em 600 vítimas mortais, 1.600 feridos e 1,5 milhões de pessoas afetadas, das quais 750 mil necessitaram de assistência humanitária urgente. Na sequência, surgiram 83.138 casos de malária, associados ao surto de cólera, que resultou em 6.727 morbidades e 8 mortes. O desastre destruiu 94 unidades de saúde nas províncias afetadas, cuja reconstrução e garantia da resiliência desse setor exigiria em torno de US\$202,4 milhões (MOÇAMBIQUE, 2019a).

Apesar de a Constituição da República de Moçambique (2004), em seu art. $89^{\circ}$ (direito à saúde), garantir que "todos os cidadãos têm o direito à assistência médica e sanitária, nos termos da lei, bem como o dever de promover e defender a saúde pública", os indicadores de saúde e nutrição só pioraram com os efeitos devastadores do ciclone nas regiões afetadas.

Do número total de assistidos, 400 mil pessoas foram deslocadas e cerca de 161 mil foram abrigadas em 164 centros de acomodação temporários nas quatro províncias da região central de Moçambique ${ }^{5}$ (MOÇAMBIQUE, 2019a).

O setor de habitação foi o mais visivelmente destruído, em razão da vulnerabilidade ambiental, social e econômica em relação aos assentamentos urbanos e rurais, que contribuíram para a destruição parcial e total de 240 mil casas, cujos danos materiais foram avaliados em US\$ 410 milhões.

4 Moçambique é um Estado unitário com uma divisão administrativa de províncias, distritos e localidades. A região central do país compreende as províncias de Manica, Sofala, Tete e Zambézia.

5 Das 750 mil pessoas, $53 \%$ são mulheres, $47 \%$, homens, $33,8 \%$, crianças, e 8,4\%, idosas. 
Conforme o artigo $91^{\circ}$ da Constituição de Moçambique, "todos os cidadãos têm direito à habitação condigna, sendo dever do Estado, de acordo com o desenvolvimento econômico nacional, criar as adequadas condições institucionais, normativas e infraestruturais". Verificou-se, entretanto, que o direito à moradia é também um dos mais afetados pelos desastres naturais, sobretudo em países com péssimas habitações para os moradores, tornando-os vulneráveis a riscos e desastres ambientais.

O ciclone Idai, portanto, afetou os direitos humanos, especialmente o direito à vida em razão das mortalidades, bem como o direito à moradia, por causa das habitações destruídas pelo fenômeno; e o direito à saúde e à dignidade, devido aos danos sofridos pelas instalações hospitalares e à proliferação de doenças.

Houve outros tipos de danos, sobretudo ambientais, como a perda da diversidade biológica e degradação de solos, danificação de culturas e vias de acesso, perda da biomassa com destaque para o desflorestamento, quedas de árvores de valor natural e econômico e a redução do manguezal, que permite o fluxo de sequestro de carbono.

As áreas de conservação da natureza, como o Parque Nacional da Gorongosa, reservas e a vegetação de safáris, não sofreram danos relevantes, porém podem ter provocado a movimentação forçada dos animais dos seus respetivos habitats para outros menos apropriados (MOÇAMBIQUE, 2019b).

Houve danos e perdas em outros setores considerados relevantes, principalmente o da cultura, incluindo os componentes de patrimônio edificado, sítios arqueológicos e históricos, espaços públicos, coleções culturais e suas indústrias criativas. Trata-se de peças com grande significado na vida cultural de comunidades e indivíduos. Estima-se a necessidade de recuperação do setor em US \$3,86 milhões destinados à reabilitação e restauração dos espaços culturais.

Além desses danos, o ciclone Idai destruiu diversas infraestruturas provocando o isolamento da população. A cidade da Beira, a segunda maior do país, foi a mais afetada pela intempérie, tendo registrado graves prejuízos materiais na sua estrutura urbana.

O aumento caudal dos rios Púngue, Búzi, Muda e Metuchira, que atravessam a região central do país e deságuam no Oceano Índico, provocou inundações em vastas áreas de Nhamatanda, Tica, Búzi, Dondo e cidade da Beira. A Estrada Nacional número 6 (EN6), que liga as províncias de 
Sofala e Manica ao vizinho Zimbábue, sofreu vários cortes, desabamento de pontes e erosão progressiva de terras nas suas margens.

O setor de transporte foi o que mais dano sofreu com o ciclone, avaliado em US\$ 442 milhões, seguido do setor imobiliário, em US\$ 133,5 milhões, o setor ambiental em US\$ 80 milhões e o agrícola, em US\$ 48 milhões. Estima-se o total dos danos causados em mais de US\$1,4 bilhões (a preços pré-desastre) (MOÇAMBIQUE, 2019a, p. 19).

No setor de educação, 1.372 instalações escolares foram parcial ou totalmente destruídas nas províncias de Sofala, Manica, Zambézia e Tete. Os custos financeiros dessas perdas correspondem a US\$20,4 milhões. O setor público sofreu maiores danos e perdas do que o privado, em razão do número elevado de escolas públicas e das suas condições físicas deficitárias (MOÇAMBIQUE, 2019a).

Prejuízos também para o setor produtivo foram contabilizados em US\$ 115,3 milhões, notadamente a destruição de armazéns do parque industrial, escritórios e instalações industriais.

Após a passagem do ciclone Idai, o balanço preliminar apontava para:

a) Corte geral de fornecimento de energia elétrica à cidade da Beira e arredores;

b) Corte geral de abastecimento de água à cidade da Beira e arredores;

c) Corte geral de telecomunicações entre a cidade da Beira e o resto do mundo;

d) Isolamento da cidade da Beira com o resto do país devido ao desabamento de pontes e interrupção de trânsito na EN6;

e) Elevado número de destruição de habitações, escolas e hospitais;

f) Falência do sistema operacional bancário;

g) Ruptura de stock de combustíveis e de produtos de primeira necessidade;

h) Ocorrência de focos de cólera, em razão da obsolescência do sistema de esgotos.

O grau de vulnerabilidade de Moçambique a eventos climáticos extremos exigiria medidas e políticas eficazes que pudessem mitigar os impactos das mudanças climáticas e fortalecer a resiliência populacional. As respostas internas, portanto, abrangem ações e recursos empregados no âmbito de crises por instituições (ambas formais e informais) e de indivíduos que vivem ou temporariamente residem no lugar do evento. 


\section{RESPOSTAS INTERNAS: POLÍTICAS E MEDIDAS DE PREVENÇÃO E ADAPTAÇÃO}

O governo moçambicano estabeleceu, na década de 1980, o Departamento de Prevenção e Combate às Calamidades Naturais, que incluía diferentes ministérios e tinha como tarefa principal a distribuição das ajudas entre as populações afetadas. Ao longo desse período, percebeu-se a necessidade de criação de órgãos para resolver problemas momentâneos, bem como criar estrutura técnica e institucional que prevenisse o transbordamento dos efeitos climáticos às populações. Dessa maneira, estabeleceu-se, em 1999, o Instituto Nacional de Gestão das Calamidades (INGC), responsável por conduzir esforços de mitigação, realizar campanhas de prevenção e coordenar respostas aos desastres, além de reabilitar as infraestruturas afetadas pelos desastres (ABDULA; TAELA, 2005).

Em razão da pobreza econômica foi criado o Ministério para a Coordenação da Ação Ambiental, cujo mandato visava a implementação de Estratégia Ambiental para o Desenvolvimento Sustentável de Moçambique e Erradicação da Pobreza. Nesse ministério foram estipuladas algumas vertentes para a referida implementação, tais como, desenvolvimento institucional e políticas públicas, coordenação de gestão dos recursos naturais e da área urbana, gestão integrada das zonas costeiras e educação ambiental.

No que tange à erradicação da pobreza foi criado o secretariado técnico para a segurança alimentar e nutricional, bem como o Ministério da Agricultura e Desenvolvimento Rural, com a função de desenvolver atividades mitigatórias dos efeitos da seca nas populações.

Em termos de instrumentos políticos foi aprovada pela Resolução n. 18/99, de 10 de junho, a Política de Gestão de Calamidades, tendo como um dos objetivos: "a) evitar a perda de vidas humanas e destruição de bens provocados por calamidades naturais ou pelo homem" (MOÇAMBIQUE, 1999, p. 23).

Além disso, foram aprovados compromissos internacionais em matéria de prevenção e gestão de desastres naturais, tais como a Agenda $2025^{6}$ para o Desenvolvimento Sustentável, cujo objetivo n. 11 visa "tornar as cidades e os assentamentos urbanos inclusivos, seguros, resilientes e sustentáveis". Esse objetivo está em conformidade com o Marco de Sendai para a Redução do Risco de Desastres 2015-2030, que visa "redobrar o trabalho

6 A Agenda 2025, apesar de formalmente terminar em 2025, projeta-se até 2030, quando então será feita a monitoria e o balanço de seu cumprimento. 
para reduzir a exposição e a vulnerabilidade, evitando a criação de novos riscos de desastres, bem como criar um sistema de responsabilização pela criação de riscos de desastres em todos os níveis".

Complementam ainda os instrumentos nacionais moçambicanos nesta matéria: o plano diretor de redução de riscos de desastres 2017-2030, estratégia nacional para adaptação às mudanças climáticas, introduzida através da Lei $15 / 2014$, de 20 de junho ${ }^{7}$, que estabelece o regime jurídico da gestão de risco de calamidades.

A Lei 15/2014 trata da gestão do risco das calamidades, incluindo a prevenção e a mitigação dos efeitos advindos das calamidades e o desenvolvimento de ações de socorro, assistência e recuperação de áreas afetadas. Essa lei ampliou o conceito de calamidade ao incluir incêndios, queimadas, epidemias, erosão e derrames de hidrocarbonetos, garantindo uma cobertura maior ao Plano Diretor, ao proibir "construção de habitação em zonas vulneráveis às calamidades; a obrigatoriedade do desenvolvimento da Prontidão Operacional; a obrigatoriedade do Governo em ter Plano de Contingência e de Observar os Alertas" (MOÇAMBIQUE, 2017, p. 17).

Nessa senda foi elaborada a Estratégia Nacional de Adaptação e Mitigação de Mudanças Climáticas (2013-2025), objetivando construir diretrizes de ação para criar resiliência e reduzir os riscos climáticos das comunidades, promovendo uma economia verde. De igual modo, o Programa Quinquenal do Governo 2015-2019 apresentou prioridades na busca de soluções do tema, considerando ciclones obstáculos ao desenvolvimento nacional por afetarem as capacidades instaladas do Estado.

Dessa maneira, o referido programa orienta a integração da gestão de risco de desastres e a adaptação das mudanças climáticas, com destaque para "a proteção e o empoderamento da mulher, da criança e dos grupos vulneráveis" e a "redução de vulnerabilidade das comunidades, da economia e infraestruturas aos riscos climáticos e às calamidades naturais" (MOÇAMBIQUE, 2017, p. 18).

O governo mobilizou essa estrutura normativa, política e técnica para enfrentar vários eventos climáticos extremos, dentre eles, o ciclone Idai. Nesse sentido, foi instalado o Centro Nacional de Operações de Emergência (CENOE) para coordenar as atividades e operações de emergência nacional com referência aos dois ciclones (Idai e Kenneth).

$\mathrm{Na}$ província de Sofala foi criado o Centro de Operações de Emergência (COE). O governo estabeleceu três vertentes para gerenciar os

7 Disponível em: www.ifrc.org. Data de acesso: 25/02/2020. 
riscos desse desastre: (1) Conselho de Coordenação para Gerenciamento de Desastre, comandado pelo Primeiro-Ministro, inclui todos os membros do Conselho de Ministros; (2) Conselho Técnico para Gerenciamento de Desastre, liderado pelo diretor-geral do Instituto Nacional de Gestão de Calamidades e diretores nacionais de outros setores relevantes; e (3) Centro de Operações a Emergências Nacionais, com coordenação multissetorial, além de quatro hubs de coordenação nas regiões afetadas pelo ciclone, para facilitar as operações e o intercâmbio das respostas.

Isso permitiu que o governo de Moçambique encetasse diligências e operações imediatas de salvamento e ajuda humanitária. Para tal, no dia 19 de março de 2019, declarou estado de emergência nacional. No dia 26 de março, estabeleceu o Programa de Reconstrução Pós-Ciclone Idai (PREPOC), no qual as seguintes medidas foram adotadas: aprovação do plano de reconstrução, a partir de uma abordagem pragmática e social na área de edifícios públicos e privados, equipamentos e estradas; a reconstrução de moradias feita de forma paulatina através de parceiros e sociedade civil. $\mathrm{O}$ atendimento médico e a distribuição de medicamentos conduzidos pela cadeia normal do sistema nacional de saúde e pela direção provincial de saúde de Sofala e parceiros, com o objetivo de assegurar cuidados primários às vítimas.

Pelo Decreto n. 26/2019, de 11 de abril, o governo criou o Gabinete de Reconstrução Pós-Ciclone Idai, com sede na cidade da Beira. De natureza efêmera, este Gabinete tinha o objetivo de assegurar a coordenação da avaliação dos danos, elaboração do programa de reconstrução e sua monitoria (MOÇAMBIQUE, 2019b, p. 16).

Essas são medidas cruciais de que o governo dispõe para cuidar das vítimas e mobilizar recursos para as necessidades primárias. Todavia, o país sempre enfrentou dificuldades orçamentárias e debilidades institucionais e técnicas para o cumprimento das políticas. Além disso, o impacto do ciclone Idai comprometeu as limitadas capacidades de reação desse país pobre em termos econômicos. Ciente, portanto, das suas fragilidades, o governo, através do Gabinete de Reconstrução Pós- Idai e com base na Metodologia de Avaliação das Necessidades Pós-Desastre (PDNA), solicitou apoio e parceria global ao Banco Mundial, ao Sistema das Nações Unidas, à União Europeia e ao Banco Africano de Desenvolvimento, no desenho e execução de um programa de avaliação e assistência humanitária às regiões afetadas. Em paralelo, vários países, organizações internacionais e 
organizações não governamentais, voluntariamente, ofereceram assistência e ajuda ao país em meios de salvamentos aéreos, terrestres e aquáticos, quites de emergência, montagem de hospitais de campanha e equipes médicas. Essas questões são aprofundadas na seção seguinte, como respostas internacionais no âmbito de uma calamidade natural.

\section{RESPOSTA NTERNACIONAL: AÇÕES E AJUDAS HUMANITÁRIAS}

Ajuda humanitária constitui um conjunto de reações, ações e recursos, por parte de vários atores internacionais, que visa salvar vidas, aliviar sofrimento, manter e proteger a dignidade humana durante e após as emergências (GHA, 2012).

As respostas às crises humanitárias são, portanto, emergenciais e abrangem a assistência material e serviços (acomodações, água, medicamentos); socorro emergencial e alimentar (distribuição a curto prazo e programas de alimentação suplementar); coordenação de socorro, proteção e serviços de apoio (coordenação, logística e comunicação); inclui também a reconstrução e reabilitação das regiões afetadas (GHA, 2012).

Essas ações e recursos visam garantir a dignidade humana das pessoas diante da tragédia e são fundamentais para que elas, uma vez socorridas, possam continuar no desenvolvimento de suas capacidades e na reconstrução de suas comunidades. Por isso, um dos objetivos da ajuda destina-se a "reduzir a vulnerabilidade e o fortalecimento da capacidade das pessoas e da comunidade" (GÓMEZ-GALÁN; SANAHUJA, 1999, p. 34).

De fato, essas ajudas possuem um compromisso com o mínimo existencial, cujas provisões dizem respeito à manutenção de uma vida digna. Assim sendo, a proteção às pessoas afetadas por desastres está em consonância com os objetivos da "Carta Humanitária e Normas Mínimas de Resposta Humanitária em Situação de Desastre", que garante a elas o direito a viver. Nesse parâmetro, ajuda constitui-se na dimensão primária das ações humanitárias, porque contribui para a manutenção da dignidade das pessoas, permitindo-lhes pensar a resolução dos problemas individuais e coletivos.

O grau e o volume de recebimento da ajuda humanitária variam conforme a magnitude do evento e a vulnerabilidade do país afetado, sendo 
ela de curto prazo, apenas com a finalidade de preservar a vida e aliviar o sofrimento das vítimas diretas dos desastres. Nesse sentido, o efeito da ajuda sobre a condição do país decorre da combinação com outros fatores essenciais ao desenvolvimento humano e sustentável.

Os recursos da ajuda são provenientes de governos, instituições, contribuições privadas de fundações, companhias e indivíduos, canalizados através de ONGs, programas das Nações Unidas e atividades da Cruz Vermelha, e enviados para países que enfrentam crises complexas provenientes de conflitos e desastres naturais. Esses fundos chegam aos países afetados por várias formas de transação, que podem ser da fonte oficial de um governo doador para o governo beneficiário (setor público), que inclui instituições do país doador e do governo local, organizações multilaterais e outras instituições supranacionais, além de ONGs (locais e internacionais) e organizações da sociedade civil. Nesse nível, os atores podem repassar o fundo para organizações locais implementarem as ações necessárias (GHA, 2012).

As regras de comportamento de ações humanitárias seguem os princípios de imparcialidade, independência e neutralidade, ancorados no princípio substantivo de humanidade, que visa prevenir e aliviar os sofrimentos, garantindo os direitos humanos dos afetados. Nesse parâmetro, as ações devem ser realizadas de maneira imparcial e os recursos distribuídos sem critérios de classe, sexo, raça, nacionalidade, religião ou ideário político; além disso, a ajuda não deve ser um instrumento de política externa para a consecução de interesses pragmáticos dos doadores (GÓMEZ-GALÁN; SANAHUJA, 1999).

\subsection{Ações e ajudas humanitárias pós-Idai}

Após o ciclone Idai, Moçambique recebeu apoio de organizações multilaterais especializadas nos desastres e socorro às vítimas. O Programa Mundial de Alimentos (PMA) executa ações de emergência e de desenvolvimento com foco na ajuda alimentar, de modo a reduzir a vulnerabilidade das pessoas e comunidades atingidas. O Fundo das Nações Unidas para a Criança (UNICEF) atua em colaboração com governos parceiros para diminuir a vulnerabilidade das mulheres e crianças, no contexto de desastres naturais, garantindo condições protetivas ao cuidado da saúde, educação e habitação.

O Programa das Nações Unidas para o Desenvolvimento (PNUD) presta assistência técnica ao governo no fortalecimento de capacidades 
institucionais e das políticas relacionadas aos desastres naturais. O Programa das Nações Unidas para o Assentamento Humano (UN HABITAT) dedicase à promoção social e ambientalmente sustentável das cidades, buscando fomentar abrigo adequado a todos os residentes.

A Organização das Nações Unidas para Agricultura (FAO) promove o desenvolvimento agrícola, incentivando seus estados-membros a melhorarem o sistema nutricional e a segurança alimentar nacional. O Fundo de População das Nações Unidas (FNUP) apoia países na elaboração de políticas de redução da pobreza e da promoção da igualdade de gênero. Outras organizações internacionais não governamentais foram importantes no socorro e atendimento às populações afetadas pelo ciclone Idai, sobretudo Médicos Sem Fronteiras e Save the Children.

$\mathrm{O}$ dado concreto sobre o volume financeiro recebido por Moçambique é inconclusivo, devido à dificuldade de o governo caracterizar as diferentes modalidades e níveis de transação de ajudas internacionais e também pelo fato de as populações continuarem recebendo recursos internacionais. Porém, em dezembro de 2019, o Escritório das Nações Unidas para a Coordenação de Assuntos Humanitários (OCHA) apresentou um relatório indicando que a assistência humanitária, até o referido mês, foi de US\$300 milhões para o socorro das populações afetadas.

Em torno de 1,9 milhão de pessoas receberam assistência alimentar e mais de 704 crianças foram submetidas à triagem de desnutrição aguda. Mais de 765 mil famílias foram assistidas com programas para acesso à água potável e saneamento. Cerca de 464 mil crianças receberam serviços de educação e 386 mil mulheres e meninas foram contempladas com programas sobre redução de violência baseada no gênero (OCHA, 2019).

Os recursos foram divididos conforme os núcleos prioritários criados pelo governo e parceiros internacionais. O núcleo de educação foi financiado em apenas 4\%, com US\$1,6 milhão recebido, dos US\$ 39 milhões solicitados. Ressalta-se que são necessários US\$ 8,1 milhões para as atividades dos meses seguintes, especialmente o fornecimento de espaços temporários de aprendizagem e de materiais básicos de ensino (OCHA, 2019).

Relativamente ao núcleo de segurança alimentar, 39\% foram financiados representando quase US\$ 133 milhões recebidos, dos US\$ 336,6 milhões solicitados. Ainda são necessários US\$ 32,7 milhões para implementar assistência alimentar urgente e fortalecer as próximas atividades de subsistência (OCHA, 2019).

O núcleo de saúde corresponde a apenas 4,9\%, com US\$ 1,5 milhão 
recebido, dos US\$ 30,7 milhões solicitados. Mais US\$ 4 milhões foram requisitados para cumprir as demandas recorrentes de 250 mil pessoas carentes, através de ações de vigilância comunitária de doenças e acesso básico à saúde (OCHA, 2019).

No que se refere ao núcleo de nutrição, $31 \%$ foram financiados, com US\$ 10,2 milhões recebidos, dos US\$ 32,9 milhões solicitados. Mais de US\$ 3,3 milhões são demandados para atender acima de 3 mil crianças e mulheres grávidas através de triagem para desnutrição aguda e fornecimento de suplementos nutricionais (OCHA, 2019).

As primeiras ações emergenciais para as vítimas incluíam as seguintes áreas: saneamento - construção de poços artesianos, tratamento e abastecimento de água potável e construção de latrinas. Habitação - abertura de bairros de reassentamento para construção de casas e abrigos temporários. Infraestrutura - reconstrução de escolas e unidades sanitárias, aumento de hospitais de campanha e entrega de medicamentos em zonas isoladas ou de difícil acesso.

Em seguida, foram desenvolvidas ações para fortalecer a resiliência populacional e promover a sustentabilidade, quais sejam: produção de frangos em associativismo, produção de fogões comunitários e ambientalmente sustentáveis; abertura de campos agrícolas comunitários para produção de hortaliças e milho; abertura de sistemas de microcréditos e poupança em modelos de associativismo e implementação experimental de energias limpas e renováveis (painéis solares) em bairros de reassentamento.

A disponibilidade dessas ajudas e ações foram importantes para socorrer as vítimas do ciclone Idai, porém, em que medida o governo moçambicano foi capaz de coordenar as ações e garantir a proteção aos direitos humanos das pessoas afetadas e, ao mesmo tempo, evitar que a sua segurança fosse posta em causa?

\section{OS DESAFIOS E AS ARMADILHAS DA AJUDA HUMANITÁRIA}

Quando se avalia o efeito da ajuda humanitária sobre um evento catastrófico, concentra-se no alívio do sofrimento humano e na prevenção da perda humana em larga escala. Ou seja, salvando vidas, subentende-se que a ajuda alcançou efeitos positivos em seus objetivos iniciais. Em seguida, examina-se em quais condições as vidas foram salvas e como as pessoas estão vivendo no pós-evento, visando entender se o propósito da ajuda 
humanitária coaduna com a manutenção e a garantia dos direitos humanos fundamentais. Do contrário, considerar-se-ia limitado o efeito da ajuda na recuperação do país.

A ajuda humanitária revela uma diferença enorme entre quem a fornece - normalmente um país rico, e quem a recebe - normalmente um país pobre. Não obstante a observância dos princípios comportamentais da ajuda humanitária, este ato não é totalmente isento de interesses. Há uma relação assimétrica entre doadores e beneficiários, em que os primeiros podem persuadir o Estado receptor a adotar determinadas políticas e condicionalidades (BRETT, 2016).

Essa assimetria permite a imposição de certos valores ou perspectivas de direitos humanos, inclusive a imposição de uma determinada abordagem de ajuda humanitária, criando dificuldades para a resolução efetiva do problema (DONNELLY, 1982). Ao país receptor cabe uma posição de passividade e cumprimento dos termos estipulados, caso deseje receber recursos fundamentais para o enfrentamento dos problemas (ZORMELO, 1996; MANNING; MALBROUCH, 2010).

Um dos desafios recorrentes na execução das ações humanitárias é a coordenação das tarefas. Por se tratar de um país com histórico de ocorrências ciclônicas, várias estratégias haviam sido testadas em Moçambique. Durante o intenso ciclone tropical Favio de 2007, foi adotada a Abordagem Cluster que apresentou algumas potencialidades ao reunir as demandas e problemas em núcleos. Porém, a comunicação entre os clusters não foi satisfatória, em razão do baixo número de funcionários e técnicos para acompanhar as reuniões, bem como a duplicação de clusters, o que acarretou problemas de coordenação, comunicação e desperdício de recursos (FOLEY, 2007).

No relatório supracitado, concluiu-se, através das entrevistas realizadas com os atores humanitários, a importância da assistência humanitária para o país. Entretanto, foi levantada uma questão a respeito da efetividade do modelo de assistência adotado para o caso moçambicano, em razão da magnitude da emergência e da situação da resposta nacional. Segundo Conor Foley, a questão importante é se a Abordagem Cluster foi justificada por ser mais efetiva para prover suporte ao governo e à população moçambicana, ou se tinha como objetivo servir de teste para a comunidade internacional gerenciar emergências complexas. Se a justificativa for a segunda, 
"pode-se legitimamente perguntar ao governo e ao povo de Moçambique se eles desejariam ser usados dessa maneira experimental" (FOLEY, 2007, p. 20 , tradução nossa ${ }^{8}$ ).

O sistema de ajuda humanitária tem aperfeiçoado a coordenação entre os atores e incorporado novas modalidades de ajuda, especialmente a proteção social em programas humanitários, incluindo fornecimento de dinheiro, vales e dinheiro-por-trabalho. Essas modalidades apresentam grandes benefícios ao estimular o mercado local e possibilitar aos países beneficiários a escolha de suas prioridades (GHA, 2012).

No contexto do Idai, um dos desafios foi coordenar o transporte aéreo para as regiões afetadas, que também se tornou uma opção de deslocamento dos trabalhadores, alimentos e remédios a lugares de difícil acesso. Durante as operações de emergência, alguns países ofereceram ajuda em meios aéreos e aquáticos para salvamento das vítimas. No caso dos meios aéreos (helicópteros e aviões) não havia garantias que os mesmos apenas sobrevoassem os locais afetados pela catástrofe. Moçambique não dispunha de meios tecnológicos (radares) de controle minucioso dos helicópteros e aviões envolvidos nas operações, de modo a garantir que estivessem efetivamente empenhados em missões de assistência humanitária e não em outras alheias aos interesses do país.

Em outras palavras, Moçambique não tinha capacidade suficiente para liderar a coordenação das operações de meios aéreos e aquáticos, por não possuir as tecnologias de que as grandes potências regionais e mundiais são detentoras.

O registro das pessoas é também um desafio em emergências humanitárias, devido à dificuldade de reconhecimento e identificação das que realmente foram afetadas por um evento. No caso do ciclone Idai houve uma "avalanche" de voluntários com destino às regiões afetadas, dispostos a integrar as operações de assistência humanitária, quer filiados em ONGs, quer individualmente. Contudo, depois da entrada desses voluntários no país, as autoridades de migração e alfândega deparavam-se com imensas dificuldades em controlar a movimentação interna deles, o que impediu a certificação de que esses voluntários estivessem praticando as mesmas atividades declaradas no momento da entrada e saída do país.

No relatório da missão de 2007 sobre o ciclone Favio, Conor Foley

8 If the latter answer is a substantial part of the justification, then it could be legitimately asked whether the government and people of Mozambique should have been given any say in whether they wished to be used in this experimental manner. 
considerou um problema a falta de recursos financeiros para as ONGs liderarem as operações e distribuírem os donativos de maneira efetiva. Outra questão se refere à distribuição dos alimentos, pois, quando provida de maneira coletiva, suscita manipulação política e pode não atender a grupos realmente vulneráveis, como mulheres e crianças.

A ajuda alimentar é um processo muito caro, que engloba custos de produção, transporte e gerenciamento, que variam conforme a gravidade e a localização do evento. No ciclone Idai, o acesso humanitário às diversas áreas permaneceu limitado devido aos constrangimentos de segurança e danos nas estradas, bem como ao desafio de transporte nas ilhas afetadas.

Conforme um comunicado da Human Rights Watch, quando o acesso por estrada é difícil, os alimentos ficam sob a responsabilidade dos líderes locais para que cuidem da sua armazenagem e distribuição. Entretanto, uma líder comunitária explicou que, como a "comida não é suficiente para todos, alguns líderes locais têm explorado a situação extorquindo as pessoas em troca da inclusão de seus nomes nas listas de distribuição" (MOÇAMBIQUE: VÍTIMAS..., 2019). Algumas mulheres se queixaram das listas de distribuição dos alimentos por excluírem as famílias chefiadas por elas, "em algumas aldeias, há mulheres e crianças que não veem comida há semanas" (MOÇAMBIQUE: VÍTIMAS..., 2019).

O grupo de mulheres e meninas foi considerado pelas várias organizações atuantes no ciclone Idai o mais vulnerável e desprovido de medidas e ações protetivas. Na Conferência de Beira, realizada entre maio e junho de 2019, o Consórcio Humanitário Save the Children, CARE e Oxfam (COSACA) apontou a exposição das mulheres e meninas à Violência Baseada no Gênero (VBG), no contexto pós-Idai, em razão das tarefas que elas realizam, como ter que andar longa distância para coletar água e usar banheiros compartilhados à noite em lugares de pouca iluminação.

A exposição à violência está presente também no seio familiar, resultado de tensões crescentes e necessidades para garantir produtos básicos. Esse tipo de violência coloca em risco a garantia de direitos fundamentais (acesso à escola) e o empoderamento das meninas, pois, fora do espaço escolar, elas são expostas ao casamento precoce e à violência sexual.

$\mathrm{Na}$ ocasião da Conferência Internacional de Doadores na Cidade da Beira, foi proposta uma mudança transformativa para atender às mulheres e meninas de modo a reconstruírem suas vidas. Foram sugeridas algumas medidas aos doadores: o compromisso de investirem nas redes de oportunidades, aproveitando as habilidades dos parceiros locais e das 
organizações dos direitos das mulheres; a garantia das necessidades básicas das mulheres, particularmente nos assentamentos e comunidades rurais, além de priorizar atividades geradoras de rendas lideradas pelas mulheres, garantindo-lhes segurança alimentar e a redução da desigualdade de gênero (COSACA, 2019).

A consideração dessas medidas é importante no contexto regional, onde $37 \%$ das casas são chefiadas pelas mulheres, de modo que garantir o atendimento direcionado é uma estratégia capaz de limitar o efeito do desastre natural no aprofundamento da pobreza e da violência na região e no país.

Para a prevenção da exploração e do abuso sexual, as Nações Unidas disponibilizaram uma linha telefônica de acompanhamento a esses casos e às outras formas de abuso, corrupção e fraude. Uma das vantagens é o fato de os operadores falarem os principais idiomas locais, o que facilita o fornecimento de informações e assistências (USAID, 2020).

Seis meses após o ciclone Idai, a UNICEF estimou que quase um milhão de pessoas, dentre elas 160 mil crianças, estejam enfrentando escassez de alimentos e agravamento do quadro nutricional, correndo sérios riscos de perderem a vida. Isso simboliza a incidência dos ciclones Idai e Kenneth em regiões que já enfrentavam problemas nutricionais, ratificando a fundamental continuação das ações preventivas. Por isso, algumas medidas foram reforçadas: triagem de mais de 735 mil crianças menores de cinco anos para desnutrição aguda, com mais de 400 mil a serem rastreadas até fevereiro de 2020; tratar quase 10 mil crianças desnutridas com suplementos alimentares terapêuticos; apoiar brigadas móveis inovadoras do Ministério da Saúde de Moçambique, que alcançam comunidades remotas com serviços integrados de saúde e nutrição (UNICEF, 2020).

Mais de um milhão de pessoas ainda vivem em casas destruídas ou danificadas pelos ciclones Idai e Kenneth. Quase 92,5 mil pessoas continuam deslocadas em 71 espaços de reassentamento nas regiões central e norte do país, necessitando de comida, educação e serviços de saúde. Mais recursos humanitários são requeridos para que as pessoas afetadas salvem suas vidas e sustentem suas famílias (OCHA, 2019).

\section{CONSIDERAÇÕES FINAIS}

As mais de uma centena de convenções internacionais no domínio do Direito Internacional Humanitário são complexos normativos dirigidos 
majoritariamente a conflitos interestaduais armados. Portanto, pouca atenção é dada a convenções internacionais específicas destinadas a regrar programas de assistência humanitária em casos de desastres naturais. Através delas, poder-se-ia criar uma proteção legal internacional direcionada aos estados economicamente desfavorecidos prestada por países economicamente mais robustos, com base nos princípios do Direito Internacional, tais como o respeito pela soberania nacional dos estados e a não ingerência nos seus assuntos internos, a cooperação e solidariedade, com base no princípio da boa-fé.

A partir da ocorrência do ciclone Idai, foi possível tratar de vários problemas relacionados ao processo de ajuda humanitária em países economicamente desfavorecidos. O volume dos recursos recebidos é muito importante, contudo é fundamental criar condições necessárias para o reforço da capacidade do país em cumprir as questões básicas das populações afetadas, de modo que, quando a ajuda humanitária cessar e as parcerias no âmbito da calamidade diminuírem, o governo consiga autonomamente gerenciar os próprios problemas e garantir os serviços e produtos básicos, sobretudo a salvaguarda dos direitos fundamentais.

O país ainda está tentando resolver os problemas do ciclone Idai e buscando mais ajuda humanitária. A cidade da Beira está se recuperando lentamente. As iniciativas privadas (pessoas singulares e empresas privadas) estão fazendo o possível para reabilitar suas casas e fábricas. Contudo, o setor público continua dependente do início da execução dos programas institucionais. As promessas de ajuda financeira feitas na Conferência Internacional de Doadores na Beira, em 2019, ainda não foram cumpridas, o que limita a execução do Programa de Reconstrução Pós-Ciclone Idai.

\section{REFERÊNCIAS}

ABDULA, A.; TAELA, K. Avaliação das capacidades de gestão do risco de desastres. Netherlands Climate Change Studies Assistance Programme, Phase I. Maputo, 2005.

AYLLÓN, B. P. O sistema internacional de cooperação ao desenvolvimento e seu estudo nas relações internacionais: a evolução histórica e as dimensões teóricas. Revista de Economia e Relações Internacionais, São Paulo, v. 5, n. 8, p. 5-23, jan. 2006.

BRETT, E. A. Explaining aid (in) effectiveness the political economy of aid relationships. International Development, n. 16-176, 2016. 
COSACA. Leave no one behind: ensure the needs of women and girls are prioritized at the Beira Conference 2019. Disponível em: http://policy-practice.oxfam.org.uk/publications/leave-no-one-behind-ensure-the-needs-of-women-and-girls-are-prioritized-at-the-620810. Acesso em: 12 fev. 2020.

DONNELLY, J. Human rights and human dignity: an analytic critique of non-Western conceptions of human rights. The American Political Science Review, v. 76, n. 2, p. 303-316, jun. 1982.

FOLEY, C. Mozambique: a case study in the role of the affected state in humanitarian action. London: Overseas Development Institute, 2007.

GHA - GLOBAL HUMANITARIAN ASSISTANCE. GHA Report 2012. Somerset: Development Initiatives, 2012.

GÓMEZ-GALÁN, M.; SANAHUJA, JA. El sistema internacional de cooperación al desarrollo: una aproximación a sus actores e instrumentos. Madrid: CIDEAL, 1999.

HUMANITARIANRESPONSE-MOZAMBIQUE. Disponível em: https:// www.humanitarianresponse.info/en/operations/mozambique. Acesso em: 12 fev. 2020.

INGC - INSTITUTO NACIONAL DE GESTÃO DE CALAMIDADES. Balanço da época chuvosa e ciclônica 2018-2019. Maputo: INGC, 2019.

MANNING, C.; MALBROUGH, M. Bilateral donors and aid conditionality in post-conflict peacebuilding: the case of Mozambique. Journal of Modern African Studies, v. 48, n. 1, p. 143-169, 2010.

MOÇAMBIQUE. Constituição da República de Moçambique. Maputo: Imprensa Nacional, 2004.

MOÇAMBIQUE. Informação dos danos ambientais pós ciclone. Governo da Província de Sofala, Direcção Provincial da terra, ambiente e desenvolvimento, 2019b.

MOÇAMBIQUE. Moçambique Ciclone Idai: PDNA avaliação de necessidade pós- desastre. Maputo: República de Moçambique Conselho de Ministros, 2019a. 
MOÇAMBIQUE. Plano Director para a Redução do Risco de Desastres 2017 - 2030. Maputo: República de Moçambique Conselho de Ministros, 2017.

MOÇAMBIQUE. Resolução n. 18/99, de 10 de junho de 1999. Política de Gestão de Calamidades. Disponível em: http://www.vertic.org/media/ National\%20Legislation/Mozambique/MZ_Politica_Estao_Calamidades. pdf. Acesso em: 20 jan. 2020.

MOÇAMBIQUE: VÍTIMAS do ciclone forçadas a trocar sexo por comida. Human Rights Watch, 25 abr. 2019c. Disponível em: https://www.hrw.org/ pt/news/2019/04/25/329575. Acesso em: 12 fev. 2020.

MOLENAERS, N. et al. Political conditionality and foreign aid. World Development, v. 75, 2015.

OCHA - OFFICE FOR THE COORDINATION OF HUMANITARIAN AFFAIRS. Mozambique: urgent humanitarian priorities. Disponível em: https://reliefweb.int/report/mozambique/mozambique-urgent-humanitarian-priorities. Acesso em: 20 jan. 2020.

UNICEF - UNITED NATIONS INTERNATIONAL CHILDREN'S EMERGENCY FUND. Mozambique Humanitariam Situation Report N.15 (January - December 2019). Reliefweb, 28 fev. 2020. Disponível em: https://reliefweb.int/report/mozambique/mozambique-humanitarian-situation-report-no-15-january-december-2019. Acesso em: 12 fev. 2020.

USAID - U.S. AGENCY FOR INTERNATIONAL DEVELOPMENT. Southern Africa-Tropical Cyclones. Disponível em: https://www.usaid. gov/cyclone-idai. Acesso em: 12 fev. 2020.

VALE PEREIRA, M. A. Noções fundamentais de Direito Internacional Humanitário. Coimbra: Coimbra, 2014.

ZORMELO, D. Is aid conditionality consistent with national sovereignty? London: Overseas Development Institute Portland House, 1996. 
Artigo recebido em: 31/03/2020.

Artigo aceito em: 29/06/2020.

\section{Como citar este artigo (ABNT):}

MATOS, P. A.; NDAPASSOA, A. M. O ciclone Idai e os desafios da ajuda humanitária em Moçambique. Veredas do Direito, Belo Horizonte, v. 17, n. 38, p. XXX-XXX, maio./ago. 2020. Disponível em: http://www.domhelder.edu.br/revista/index.php/veredas/article/view/1819. Acesso em: dia mês. ano. 